\title{
PECULIARITIES OF PSYCHOLOGICAL WELL-BEING OF LITTLE TOWN AND METROPOLIS STUDENTS: SOCIOCULTURAL ASPECT
}

Irina Loginova, Oksana Gavrilyuk, Yulia Zhivaeva, Krasnoyarsk State Medical University named after professor Voino-Yasenetsky, oksana.gavrilyuk@mail.ru

\begin{abstract}
Current social situation unpredictability causes difficulties for modern students in both meeting the requirements of society and keeping their well-being. This study aims at revealing the sociocultural aspect of psychological well-being in Russian little town and metropolis students. The method of "Psychological Well-being Scale", adapted from the questionnaire "The scales of Psychological Wellbeing" of Ryff, the method of "Personal and Social Identity" of Urbanovich and the Mehrabian Achieving Tendency Scale in modification of Magomed-Eminov were used in this study. The received data indicated that average and low levels of psychological well-being were more characteristic for little town students in case of correlation between their motivation to avoid failure and negative sociocultural identity. These findings seem to be largely resulting from depriving regional conditions and may be considered as an indicator of this deprivation.
\end{abstract}

UDC Number: 159.923, 378.12, DOI: 10.12955/cbup.2013.42

Keywords: psychological well-being, little town, metropolis, students.

\section{Introduction}

Being a core component of psychological stability, a positive self-image is mostly ensured by positive personal identity. If social environment factors empower people, promote self-realization and provide psychological support, all this as a whole contributes to the formation of their positive identity and thus personal resilience. The importance of psychological stability factors increases during sharp social and economic fluctuations. In particular, it is manifested in aggravation of the need to belong to a group (sociocultural identity). The person always needs to feel as a part of "we", a part of any group. Realizing their belonging to a group, people feel supported. Positive identity ensures perception of the world around as more stable, more reliable, fair, and well-balanced. Achievement of one's own positive sociocultural identity facilitates recognizing and appreciating one's own uniqueness in the world, as well as understanding one's own ego boundary, one's opportunities and vital prospects. On the contrary, loss of one's own positive identity disorganizes one's inner world, breaking its stability and reducing psychological well-being. In the context of current social unpredictability psychological well-being problems are reported to be more common for university students than across general populations (Adams et al., 2006; Cooke et al, 2006; Mahajan, 2011; Loginova et al., 2012; Negovan, 2010; Topham \& Moller, 2010). The purpose of this study was to identify the sociocultural aspect of psychological well-being in modern Russian little town and metropolis students. 


\section{Literature review}

The issue of positive psychological functioning has become the object of psychologists' increased interest since the middle of the 20th century. In existential and humanistically focused psychology this problem bears a relationship to the principle of integrity in approach to understanding of the personality. The issue also associates with interpretation of personal existence as the unique integrity possessing one's unique life experience, one's inner world, one's unique reaction to life circumstances, manifested in an originality of one's vital self-implementation (Loginova, 2009). Such approach demands introduction of a concept that would characterize both extent of one's positive functioning, and degree of self-satisfaction with oneself and one's own life. It is psychological wellbeing that seems to be such an indicator of the personality.

The problem of studying of various aspects of personal psychological well-being has drawn the attention of researchers since 60th years of the last century (Bradburn, 1969). Then there were a number of the original theories describing the nature and structure of psychological well-being (Ryff \& Singer, 1996; Keyes, 1998), thereby overcoming the narrowness of the health / illness dichotomy for the description of various aspects of positive psychological functioning.

\section{Data and Methodology}

The sample comprised 146 undergraduate students from Lesosibirsk Pedagogical University, 146 students from Krasnoyarsk State Pedagogical University, and 96 students from Krasnoyarsk State Medical University, a total of 388 first-, second-, third-, and fourth-year full-time students. The respondents' mean age was 19.7 years old. All these students were invited to participate in this study on a voluntary basis. They were assured that the data collected would only be used for the sole purpose of the study.

On the preparatory stage of the investigation the method of "Personal and Social Identity" of Urbanovich (2005) and the Mehrabian Achieving Tendency Scale in modification of MagomedEminov (1987) were used. Studying the level of student well-being as a diagnostic tool we have used the method of "Psychological Well-being Scale", adapted by Fesenko (2005) from the questionnaire "The scales of Psychological Wellbeing” of Ryff (Ryff \& Keyes, 1995).

\section{Results and Discussion}

According to the results of the Method of "Personal and Social Identity" of Urbanovich, used on the preparatory phase of the investigation, positive personal identity was revealed in 79 students $(53.72 \%$ of the respondents) from Lesosibirsk Pedagogical University, in 102 students $(69.9 \%$ of the respondents) from Krasnoyarsk State Pedagogical University, and in 70 students $(73 \%$ of the respondents) from Krasnoyarsk State Medical University. Negative personal identity was revealed in $46.28 \%$ of the students from Lesosibirsk Pedagogical University, in $30.1 \%$ of the respondents from Krasnoyarsk State Pedagogical University, and in $27 \%$ of the students from Krasnoyarsk State Medical University.

Students with positive personal identity turned to be more adjusted to the real world. They understood that both their personal traits and their social status objective indices played an important role in their ego boost and perception of success. Among the distinctive cues of these students were increase of 
awareness of psychological me and perceptions of one's future, enhancement of these perceptions emotional depth and expansion in their number. Students of this type turned to be future oriented; they had their particular vision of their future, where the main social values were represented. Realist's way of thinking about future and the presence of sociocultural aspect in one's vision of the future were characteristic to these students.

Students with negative personal identity did not completely accept their social environment and did not try to resist to problematic situations they face. Low adaptiveness to new life conditions, inability to readjust oneself to actuality and to change one's attitude towards social variations were characteristic to this type of students. They hardly had their particular vision of their future, and they did not associate their future with their actual social environment.

According to the results of the Mehrabian Achieving Tendency Scale in modification of MagomedEminov (1987), achievement motivation was revealed in 14 students ( $9.52 \%$ of the respondents) from Lesosibirsk Pedagogical University and in 26 students (17.68 \% of the respondents) from Krasnoyarsk State Pedagogical University. Accordingly, motivation to avoid failure was revealed in $90.48 \%$ of the students from Lesosibirsk Pedagogical University and in $82.32 \%$ of the students from Krasnoyarsk State Pedagogical University. Among the students from Krasnoyarsk State Medical University achievement motivation predominated in 23 persons (24\%), whereas motivation to avoid failure was revealed in 73 persons $(76 \%)$.

The objective of the next step of our investigation was to find out the peculiarities of sociocultural identity depending on the manifestation of achievement motivation. For this purpose we analyzed the investigation results according to the following scheme:

The results of our study showed that $9.52 \%$ of the students (14 persons) from Lesosibirsk Pedagogical University had achievement motivation. And accordingly, motivation to avoid failure was revealed in $90.48 \%$ of the students. Moreover, positive sociocultural identity was typical for $53.72 \%$ of the respondents (79 students). Thereafter, $46.28 \%$ of the students from Lesosibirsk Pedagogical University demonstrated negative sociocultural identity. Positive sociocultural identity was revealed in all the respondents with achievement motivation (14 persons). Consequently, we found out that among 79 respondents with positive sociocultural identity, there were 14 students $(17.64 \%)$ with achievement motivation.

Among the students from Krasnoyarsk State Pedagogical University 17.68\% (26 persons) demonstrated achievement motivation and $82.32 \%$ of the respondents showed motivation to avoid failure. Positive sociocultural identity was revealed in 102 students (69.9\% of the respondents) and negative sociocultural identity - in $30.1 \%$ of the students. Among 102 respondents with positive sociocultural identity, there were 26 students $(25.5 \%)$ with achievement motivation.

A total of 23 students (24\%) from Krasnoyarsk State Medical University had achievement motivation. And accordingly, motivation to avoid failure was revealed in 73 persons (76\%). Positive sociocultural identity was typical for 70 students ( $73 \%$ of the respondents) and negative sociocultural identity was revealed in 26 students ( $27 \%$ of the respondents). Positive sociocultural identity was revealed in all the respondents with achievement motivation (26 persons). Thus, we found out that all the respondents (70 persons) with positive sociocultural identity had achievement motivation.

On the main phase of the investigation, we divided the students' groups into the following subdivisions: 
1. Positive sociocultural identity, achievement motivation.

2. Positive sociocultural identity, motivation to avoid failure.

3. Negative sociocultural identity, achievement motivation.

4. Negative sociocultural identity, motivation to avoid failure.

According to the data received from the investigation of the first subdivision we estimated the degree of manifestation of student well-being components. High and standard values were indicative of familiarity and trust relationship with the neighborhood, readiness to care about the outer world, ability to empathize and interpersonal relations skills. Moreover, this characteristic included desire to be flexible in interaction with others and ability to reach a compromise. Absence of this trait was indicative of loneliness, inability to establish and maintain trust-based relations, unwillingness to accept a compromise, social withdrawal, which was not characteristic for the respondents from this subdivision. These characteristics were more manifested in metropolis students (Krasnoyarsk State Pedagogical University and Krasnoyarsk State Medical University).

Analyzing the results of the investigation of the second subdivision students, we revealed law and average indices of psychological well-being. Sence of confidence, competence to control the daily round, ability to make the best use of diferent life circumstances, to choose and create an appropriate context for the realization of personal needs and values as well as ability to carry out different types of activity were peculiar both for little town (Lesosibirsk) and metropolis (Krasnoyarsk) students from the second subdivision. In addition students of this subdivision demonstrated lack of life goals clearness; some of them had not their own views and convictions assigning a specific meaning of life. There were some students in the group who felt dissatisfied with themselves. They were disappointed with their own past, overanxious about some of their individual attributes and did not accept themselves. Desire to become other persons, not like they are in reality, was peculiar to them.

We did not reveal any students who might belong to the third subdivision. As for the respondents of the fourth subdivision, most of them demonstrated law indices of psychological well-being, indicative of their inability to establish and maintain trust-based relationships, unwillingness to compromise, and unsociability. Results on the Autonomy scale showed that these students turned to be overanxious about their external evaluation and expectations of the others, preferred to be guided by the others while making crucial decisions and demonstrated their inability to resist to social pressure on mind as well as in real activity. Analyzing the results received from the Environmental Mastery scale allowed us to come to the following conclusions: the respondents of this subdivision had difficulties in managing the responsibilities of their daily life, felt incapable to improve or change their entourage, and did not feel control over the outside world. They were disappointed with their own past, overanxious about some of their individual attributes and did not accept themselves. They wished to become other persons, not like they are in reality.

\section{Conclusion}

This study allowed us to define integral indicator of the degree of the students' orientation at the realization of the positive functionning components, as well as the degree of this orientation implementation, demonstrated in sense of happiness, personal and life satisfaction. Thus, analyzing different scales of the results received in Lesosibirsk Pedagogical University, Krasnoyarsk State Pedagogical University and Krasnoyarsk State Medical University, we can observe the following regularity. 
The findings revealed that both little town and metropolis students had high and standard levels of psychological well-being in case of correlation between their achievement motivation and positive sociocultural identity. Average and standard indices of psychological well-being were more common in little town students having motivation to avoid failure, provided that they had positive sociocultural identity. Average and low indices were more indicative in little town students in case of correlation between their motivation to avoid failure and negative sociocultural identity.

These findings seem to be largely resulting from depriving regional conditions and may be considered as an indicator of this deprivation. In a region with poor conditions for self-fulfillment, the level of self-fulfillment in many people is in arrears of the level of their self-fulfillment need. According to the typology of Galazhinsky (2002), this level of self-fulfillment may be defined as reproductive-adaptive. However, as our research results showed, in a real life people with a higher level of self-fulfillment approve themselves actively and differently even under conditions of a little town.

\section{References}

Adams, G. R., Berzonsky, M. D. \& Keating, L. (2006). Psychosocial resources in first year university students: The role of identity processes and social relationships. Journal of Youth and Adolescence, 35 (1), 81-91. http://dx.doi.org/10.1007/s10964-005-9019-0

Bradburn, N. (1969). The Structure of Psychological Well-Being. Chicago, IL: Aldine Publishing Company. PMid:5818525

Cooke, R., Beewick, B. M., Barkham, M., Bradley, M. \& Audin, K. (2006). Measuring, monitoring and managing the psychological wellbeing of first year university students. British Journal of Guidance \& Counselling, 34 (4), 505-517. http://dx.doi.org/10.1080/03069880600942624

Fesenko, P. P. (2005). Osmyslennost' zhizni i psikhologicheskoe blagopoluchie lichnosti [Life understanding and psychological well-being]. (Doctoral dissertation). Moscow, Russia: Moscow City Pedagogical University (MCPU).

Galazhinskiy, E. V. (2002). Sistemnaya determinatsiya samorealizatsii lichnosti [Systemic determination of personal self-fulfillment]. (Doctoral dissertation). Barnaul, Russia: BSPU Barnaul State Pedagogical University.

Keyes, C. L. M. (1998). Social well being. Social Psychology Quarterly, 61 (2), 121-140. http://dx.doi.org/10.2307/2787065

Loginova, I. O. (2009). Psychologia zhiznennogo samoosushchestvleniya [Psychology of life selffulfillment]. Moscow, Russia: SSU.

Loginova, I. O., Chupina, V. B. \& Zhivaeva, Y. B. (2012). Sociocultural Characteristics of Psychological Education in the Context of Systemic-Anthropological Approach. Journal of Social Sciences, 8, (2), 281-293.

Magomed-Eminov, M. S. (1987). Motivatsiya dostizheniya: struktura i mekhanizmy [Achievement motivation: structure and mechanisms]. (Doctoral dissertation review). Moscow, Russia: Moscow State University. 
Mahajan, E. \& Rastogi, R. (2011). Psychological Wellbeing of Students with Type A and Type B Personalities. The IUP Journal of Organizational Behavior, X (1), 57-74.

Negovan, V. (2010). Dimensions of students' psychosocial well-being and their measurement:

Validation of a students' Psychosocial Well Being Inventory. Europe's Journal of Psychology, 2, 85104.

Ryff, C. D. \& Keyes, C. L. M. (1995). The structure of psychological well-being revisited. Journal of Personality and Social Psychology, 69, 719-727. http://dx.doi.org/10.1037/0022-3514.69.4.719 PMid:7473027

Ryff, C. D. \& Singer, B. (1996). Psychological well-being: meaning, measurement, and implications for psychotherapy research. Psychotherapy and Psychosomatics, 65 (1), 14-23.

http://dx.doi.org/10.1159/000289026

Topham, P. \& Moller, N. (2010). New students' psychological well-being and its relation to first year academic performance in a UK university. Counseling and Psychotherapy Research, 11 (3), 196-203. http://dx.doi.org/10.1080/14733145.2010.519043

Urbanovich, A. A. (2005). Psikhologiya krizisov sotsial'noy identichnosti lichnosti [Psychology of social identity crises]. Minsk, Belorussia: Akademiya MVD Respubliki Belarus. 